\title{
Extending the string-of-lights metaphor to describe dynamism in agricultural landscapes
}

\author{
Robert C. Corry 1
}

Received: 30 November 2017/ Accepted: 25 May 2018/Published online: 16 June 2018

(C) Springer Science+Business Media B.V., part of Springer Nature 2018

In their 1986 book, Landscape Ecology, Forman and Godron introduced the string-of-lights metaphor to help readers visualize connected patches and imagine metapopulations. The metaphor can be used to explain and anticipate sequential landscape change too. When changes in landscape structure can be anticipated it means that the ecological consequences might be less surprising and can be prepared for. An example is how changes in agricultural landscapes-particularly in crop production and rotation sequences-represent rapid dynamism that is often overlooked in landscape ecology yet has influential consequences. If annual crops are rotated with perennial forages, landscape patterns change frequently. Because crop rotations are a form of predictable landscape change, future agricultural landscapes can be anticipated from any point in a sequence, allowing landscape ecologists to peer forward. The string-of-lights metaphor offers an elegant basis for interpretation of dynamic landscapes, but it has not achieved popular application. Here I

Electronic supplementary material The online version of this article (https://doi.org/10.1007/s10980-018-0658-4) contains supplementary material, which is available to authorized users.

\section{R. C. Corry $(\bowtie)$}

Centre for Land \& Water Stewardship, Landscape

Architecture, Ontario Agricultural College, University of

Guelph, Guelph, ON N1G 2W1, Canada

e-mail: rcorry@uoguelph.ca describe and extend the string-of-lights metaphor to apply to ecological problems associated with rapid changes in landscape composition. Untangling the metaphor can help landscape ecologists propose desired changes. Modifying landscape sequences is opportune because even minor modifications that design new landscape pattern dynamics can aggregate to broad functional outcomes.

\section{Introduction to the string-of-lights metaphor}

Forman and Godron (1986) stated their metaphor using two terms: the string-of-lights and the string-ofbeads. Landscape design and planning uses similar metaphors to describe designed patterns like Boston's "emerald necklace" of connected parks or the "greenbelt" systems encircling cities such as Ottawa. The string-of-lights was characterized as, " $a$ pattern consisting of a series of nodes attached to a corridor" (p. 600). Forman and Godron (1986) casually noted that the string-of-lights might relate to connectivity for recolonization after local extinctions, making it a useful metaphor for metapopulations too.

While the metaphor was introduced using both "beads" and "lights" in the string (Forman and Godron 1986; p. 127), the implications can be different. The inanimate nature of beads equates to characterizations like an emerald necklace or a rope 
with knots-using a literal visualization of the metaphor (Fig. 1a). Alternatively, lights have at least binary characteristics that allow them to be imagined as lit or not, and perhaps with variable attributes such as brightness. The binary characteristics lead to two extensions of the metaphor: that the lights can be turned on or off, and that the rates or durations for which they are turned on or off can vary.

While the string-of-lights was not originally described with animated characteristics, the interpretation is made even more powerful if the string is imagined as a whole metapopulation: inhabited patches are imagined as light bulbs that are illuminated, and uninhabited patches are those that are dark, functionally connected by a circuit for dispersal (Fig. 1b). The dynamics of metapopulation structure are easily imagined as a string-of-lights where bulbs blink on and off over time representing recolonizations and local extinctions (Hanski 1998). As long as some bulbs are illuminated at any point, the metapopulation remains extant; if the entire string-of-lights goes dark, it is extinct.

Further, rates of recolonization and extinction can be implied by the rates at which lights blink on and off. Each light can be imagined as a sub-population, somewhat independent of the others, but with the explicit connection among them-the string that represents a functional linkage. Some light bulbs might remain illuminated for extended periods, while others may be dark and only infrequently lit, suggesting something about a subpopulation's viability within the metapopulation (Opdam et al. 1993). The dynamic equilibrium of the metapopulation is based on the subpopulations and implied by the number of lights that are illuminated on the string and the rate at which they blink on and off.

A final variation of the basic metaphor is that the brightness of the lights on the string can change. Intense light might imply high-quality source habitats where sub-populations thrive with high viability, whereas dimly-lit bulbs could be low-quality habitats that consistently act as sinks. Collectively an animated string-of-lights could be used to imagine many attributes of metapopulation structure as light bulbs blink on and off at different rates and have different intensities of light. Observing a string-of-lights over time would give a sense of its dynamics—of which bulbs were more frequently illuminated and bright, and which bulbs seem to be nearly always dim or dark, and the rates at which the entire string-of-lights changes its appearance.

A critique of this established metaphor is that even while it can be extended to show rates of change, occupation or vacancy, and imply quality, its interpretation remains limited to a single variable-like the presence of a species, guild, or type. If the metaphor could be adapted to conceptualize insights into additional variables it might extend its usefulness.

\section{String-of-colored-lights metaphor}

A practical extension of the string-of-lights, beyond their animation, is imagining that the bulbs can change color-a common feature of decorative light-emitting diode (LED) strings. If colors of the lights provide some information about landscape characteristics, the metaphor's usefulness expands (Fig. 1c). For example, a predator-prey relationship can be represented through different color sequences: red for predator alone, green for prey alone, and yellow for both predator and prey occupying a single patch. Now as the string-of-lights is observed the predator-prey metapopulation dynamics can be interpreted throughout a landscape, and some outcomes become relatively predictable (predators without prey lead to local extinctions, so red lights go dark more than yellow or green lights).

Applying the string-of-colored-lights to vegetation succession could be useful for basic ecological instruction. A typical sequence of colonization of substrate to rise of herbaceous and woody plants could be easily imagined as a transition of lights in a colorchanging sequence that might show diminishing pioneering species in favor of late-successional species as a warm-to-cool color sequence. In a similar way the adaptive cycle of ecosystem functions (Holling, in Gunderson et al. 1995) or vegetation succession after forest fires could be illustrated using this metaphor. The string-of-colored-lights can help people imagine challenging problems of landscape dynamics such as changes in landcover or species composition by applying normative expectations for the light bulbs' colors, intensity, rate and duration of blinking, and how much of the entire string is illuminated with a desired balance of colors over time (Fig. 1d). 
Fig. 1 The string-of-lights and colored-string-of-lights metaphors described using literal/structural and conceptual/functional interpretations. In the lefthand panes (a and b) lights can turn on or off. In the right-hand pane (c and d) lights can turn on, off, and change color. Solid lines are structural connections; dashed lines are functional connections

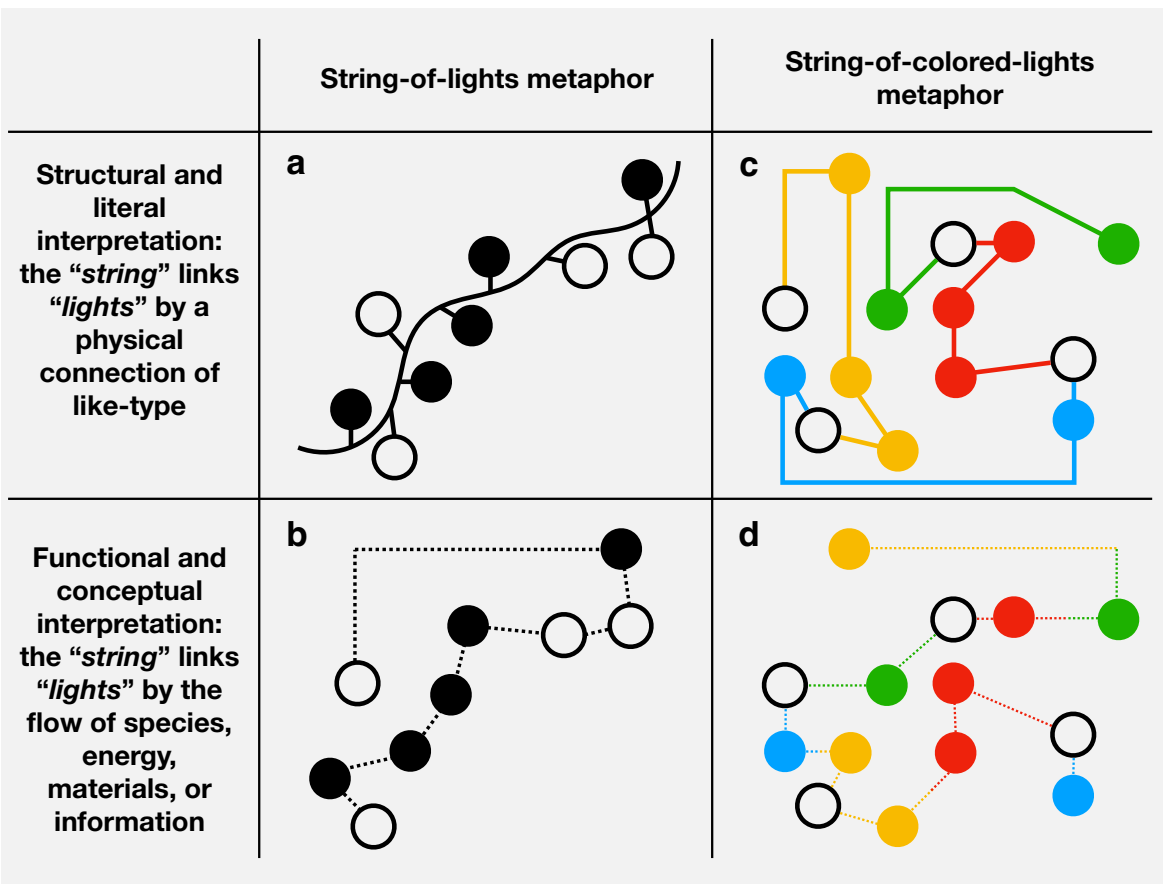

Applying landscape ecology to achieve societal benefits requires the use of plain language that can communicate critical ideas well (Cachelin et al. 2010). Metaphors like the "emerald necklace" or "greenbelt" are simple imagination devices that connect fundamental patterns for understanding and application. Using the string-of-colored-lights metaphor, this perspective paper examines the dynamism of landscape composition to show how small adjustments to the number of illuminated lights, their rates of blinking, intensities, or colors can be consequential for societal expectations. Agricultural landscapes are the focus of the example because of their unique dynamics and broad consequences.

\section{Agricultural dynamics in North America}

Agricultural landscapes are dynamic across multiple time scales. In central North America the soils derived in post-glacial, pre-settlement ecosystems now grow broad fields of grain or oilseed crops, vegetables and fruits, "tame" forages, or are grazing lands. Over a period of years to several decades, new crops emerge and their uses expand such that they become a more ubiquitous part of the farm landscape while other crop landcovers contract in area as they fall from favor.
In a human lifetime a region's agriculture might transition from extensive grazing livestock to intensive feeding operations that preclude the need for grazing landcovers (e.g., confined cattle or hogs that are fed grains across central North America; Potter et al. 2010), or from conventional tillage to reduced tillage practices (Fuglie 1999). Time scales for dynamism in agricultural landscapes include some of the shortest of any landcover types when they consider the annual or sub-annual changes due to crop establishment and harvest sequences. Understanding how these frequent, rapid conversions among different crops affects landscape patterns is fundamental in order to estimate the ecological functions of agricultural landscapes- including the life cycles, seasonality, and persistence of different landscape compositions (Corry 2018).

Landscape ecology is fundamentally focused on landscape pattern and change, recognizing cultural conventions in intensively-modified landscapes. Opdam et al. (2013) said that "landscape ecology must consider how knowledge about pattern-process dynamics may constructively interact with societal processes... Knowledge of environmental processes alone is not sufficient; knowledge of human behavior, values, and norms is essential to understanding the dynamics of coupled human and natural systems" ( $\mathrm{p}$. 
1440). A normative practice in the expanse of agricultural landscapes is crop rotation: rotations may be the most-common conservation practice within farming (Lin 2011). Crop rotations are the sequencing of vegetation in the same location over time, defined by the Soil Conservation Society of America as, "the growing of different crops in recurring succession on the same land" (1982, p. 38). In order to achieve a more ecologicallyfunctional agriculture - or at least to address undesirable consequences of cropping-landscape ecology must consider temporal dynamics that result from agricultural conventions. The expanse of cropland around the earth constitutes civilization's largest human-natural system (Ramankutty et al. 2008), composed and configured according to our behaviors, values, and norms.

Crop rotations are not a farmer's random selection of landcovers from a menu of possibilities - they are intentionally-selected sequences based on knowledge and preferences including agronomy, economics, enterprise types and needs, and available labor and production equipment. That is, they "draw on the experiences of stakeholders and practitioners" (Opdam et al. 2013 p. 1440). If an observer watched a particular location-a field-over several years they are likely to witness intentional change in cover types in each growing season: at the end of the observation period a "typical" rotation might become apparent. If that same field came under new ownership or management or if agricultural markets shifted, the rotation might change to accommodate a different intent.

Compared with croplands, no other landscapes have such a clearly-defined transition among landcovers on the basis of seasons. That the vegetative cover will be destroyed and re-established in a highlypredictable sequence and timeframe is unique to agricultural landscapes including those which dominate central North America (Franzluebbers et al. 2014). This sequence is related to consequences that include some undesired by society (Lockeretz 1997; Nassauer and Kling 2007). Addressing this dynamism is therefore fundamental to understanding and responding to societal concerns like pollinator conservation, greenhouse gas fluxes, biodiversity loss, soil degradation, food access, safety, and sovereignty, fate of pesticides and nutrients, and water quality across the majority of the continent's center. Levering the dynamism and composition within crop rotations might be a powerful means to enhance societal benefits from agriculture.

Rotations are a design innovation in agriculture. Prior to the advent of chemical fertility, and in particular industrial nitrogen fixation via the HaberBosch process (Smil 2001), rotations with nitrogenfixing legumes were considered essential in cropping (Waters 1915; Franzluebbers et al. 2014). The agronomy behind nutrient availability, weed, fungus, and insect pest control, and crop harvest and establishment timing has resulted in a well-considered and thoroughly-intentional sequence to meet the needs of the farmer. Landscape design has been defined as, "intentional change of landscape pattern, for the purpose of sustainably providing ecosystem services while recognizably meeting societal needs and respecting societal values" (Nassauer and Opdam 2008, p. 835). From the perspective of farmers, this intentional change in vegetation each growing season sustains agricultural production meeting their needs and respecting their values of productivity and pest control. While the sustainability and societal reach might be limited in a farmer's actions, the intentional change in landscape pattern for a particular service of productive yield is a universal goal of crop rotations.

\section{Agriculture's ecological consequences and the role of cover type}

Conservation and regulation within agriculture have attempted to address many of the undesirable consequences of cropping. These include soil degradation, habitat conversion and loss of species diversity, nonpoint source pollution (including greenhouse gas emissions), fate of pesticides and degradates in water, soil, and crops, and eutrophication and hypoxia in receiving waters (Lockeretz 1997; Tilman et al. 2002; Santelmann et al. 2007; Eilers et al. 2010). Applied conservation has worked in an organized and earnest way for more than 80 years in central North America: for example, the USDA Soil Conservation Service was established in 1935 as a response to the soil erosion of the "Dust Bowl" and some of the earliest conservation programs helped to establish perennial vegetation to reduce soil erosion across the US Midwest, Great Plains (Steiner 1990), and Canadian Prairie provinces (Sparrow 1984). 
In spite of conservation programs and public subsidies, undesirable ecological consequences remain-sometimes even increase-in part because intensive agricultural practices change the crops, production techniques, and conservation measures as well as non-farmed land within a farm's boundaries. In the western Corn Belt (USA), perennial grasslands within the Conservation Reserve Program and grazing lands were recently rapidly converted to annual rowcrop production (mostly corn) in a period of a few years coincident with US policies supporting ethanol from corn starch (Schnepf and Yacobucci 2012; Wright and Wimberly 2013). A similar outcome occurred in southern Canada where incentives for ethanol from corn starch (Dessureault 2014) were coincident with conversion of perennial forages to annual row crops in agricultural landscapes near ethanol refineries (Corry 2018). Losses of soil-conserving perennial cover as part of conservation programs, forages, and pastures have been rapid since the early 2000s in the US Midwest (Stuart and Gillon 2013).

A blunt but effective categorization of landcovers within crop rotations is the binary classification as annual or perennial vegetation (Schulte et al. 2006; Lin 2011; Asbjornsen et al. 2013; Corry 2016). Typical vegetation within Midwestern, USA or Great Lakes basin of Canada includes corn, soybeans, cereal grains (e.g., wheat, oats, barley), hay, and pasture. Corn, soybean, and cereal grains are annual monocultures. Hay is perennial and might be a monoculture (alfalfa), biculture (a mix of alfalfa and a grass), or polyculture (alfalfa and other legumes, blend of grasses). Pasture is a perennial polyculture (mix of legumes and grasses, along with incidental herbs or sparse woody vegetation).

Over the long-term, perennial vegetation has consistently led conservation and stewardship performance within agriculture (Steiner 1990; Dunn et al. 1993; Lemaire et al. 2015). While continuous living vegetative cover (or "relay crops") and sacrificial "cover crops" are improvements within annual cropping systems, they are mitigation measures for cultivation of annual crops that continues to be problematic (Soule and Piper 1992; Jackson 2010). Perennial vegetation remains a leading approach for many conservation goals (Schulte et al. 2006; Russelle et al. 2007; Franzluebbers et al. 2012; Munkholm et al. 2013; Liebman and Schulte 2015; Blanco-Canqui and
Francis 2016). Its type (e.g., herbaceous or woody), location, and management are key attributes to generating the most benefits from perennial cover in agriculture (Lin 2011) - either as productive parts of farms (termed "working lands") or as ecosystem service providers (e.g., non-farmed land) within farm boundaries (Schulte et al. 2006).

As an example of the perennial-annual dichotomy, the Conservation Reserve Program in the USA converted annual crop cover on highly-erodible soils to perennial vegetation for 10 years (as an ecosystem service provider) and was shown to reduce soil erosion, improve surface water quality, benefit wildlife populations, and stabilize farm incomes (Dunn et al. 1993; Randall et al. 1997; Henningsen and Best 2005; Burger et al. 2006; Riffell et al. 2008). Perennial cover as part of crop rotations has been shown to decrease soil erosion, nitrate nitrogen loss, and tile drainage volume, and enhance water infiltration and percolation, and crop yield and stability (Randall et al. 1997; Huggins et al. 2001; Congreves et al. 2014; Gaudin et al. 2015). In sum, "agricultural soils will benefit from the re-introduction of perennial grasses and legumes into the landscape (i.e., temporally and/ or spatially)" (Franzluebbers et al. 2014, p. 24).

\section{Strategic perennial cover}

To consider how perennial cover affects ecosystem and cultural services in the landscape, the disproportionate benefits hypothesis (Asbjornsen et al. 2013) postulates a relationship between the amount and location of perennial cover and the extent of services provided by it. The hypothesis suggests that strategically locating perennial cover in farm landscapes yields higher benefits than locations that are not strategic. This applies particularly to mid-points of proportions, or where the landscape has intermediate complexity (Tscharntke et al. 2012). At high or low proportions, the benefits converge whether the location is strategic or not (Fig. 2). Conversely, annual cover can have disproportionate costs depending on where it occurs in the landscape (Corry 2016).

Agricultural conservation programs in North America are not always strategic about the location of perennial or annual cover, even as the hypothesis suggests that auspicious locations can provide additional benefits. Exceptions are conservation programs that encourage perennial cover on highly-erodible 


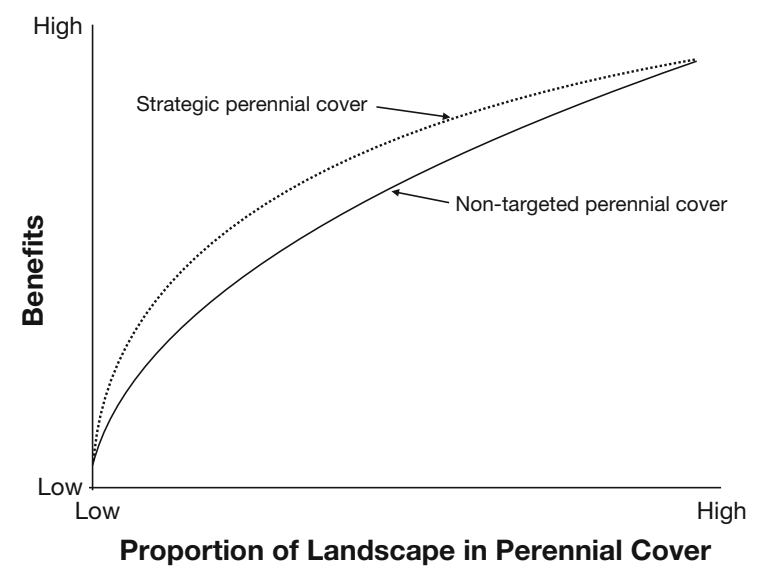

Fig. 2 The disproportionate benefits hypothesis (from Asbjornsen et al. 2013) suggests that strategic integration of perennial cover provides more societal benefits than nonstrategic approaches, especially for landscapes of intermediate complexity (at intermediate proportions)

soils, at the bottom of slopes, adjacent to surface waters, or where at-risk species are losing habitats; all are strategic locations that can enhance environmental benefits.

The disproportionate benefits hypothesis is applied to an unspecified landscape extent-an area of land where perennial proportions can be measured and the outcomes assessed. Because the area of consideration is not explicit, it could be at the farm, landscape, or regional scale. While this hypothesis is spatial- "the positive impact of perennial plants can be magnified when perennials are targeted to landscape positions that yield disproportionately high [ecosystem services] benefits relative to the area they occupy" (Asbjornsen et al. 2013, p. 102)_it can also be temporal. If the hypothesis is applied to a single time point, a period of time, multiple points or periods, or continuously, the range of perennial proportions across space would differ as would resulting services.

Measurements across a kilometres-wide landscape and across decades would show changes in proportions of perennial cover-for example, decreases in the US Midwest (Brown and Schulte 2011) and Great Lakes basin (Corry 2018), and increases in re-foresting parts of New England, USA (Thompson et al. 2013) and Quebec, Canada (Pan et al. 1999). But measurements at the scale of a farm or for short durations might counter regional trends depending on the farmer's enterprise and management approaches. An example of a counter-trend might be a farm property managed as a single unit (i.e., field) with a rotation of three annual crops in sequence with perennial forages for the subsequent 3 years: at the fine time scale between the 3rd and 4th growing season the trend appears to be rapid conversion of annual crops to perennial forages regardless of trends on neighboring lands (a broader spatial scale). Comparing a single point of this sequence to another single point 3 years later could lead to dramatically different inferences.

As perennial proportions in a part of the landscape increase or decrease, a corresponding change elsewhere might mitigate overall changes. For example, cropping an erodible soil in one location might be compensated for by establishing perennial vegetation in another so that some of the benefits, like carbon sequestration, visual amenity, or grassland habitat remain. According to the disproportionate benefits hypothesis, varying the area of perennials might be able to compensate for strategic locations: a small area of perennial cover in an auspicious location might provide benefits equal to a larger area of perennial cover in a less-critical location. Some locations, though, might have no equal (Forman 1993). It might also be that perennial cover could exist at a strategic time when it can provide desired benefits, such as increasing the area of perennial forage during a cycle of incentives for corn-starch ethanol, or throughout the period of successful reproduction of grassland birds (concluding about July 15 in mid-latitude North American farmlands; Best et al. 1995; Freemark 1999).

Instead of only strategic locations and proportions of area, the hypothesis could be based on strategic times and proportions of the overall sequence. For example, a soil vulnerable to erosion might be in a rotation that provides for perennial cover for $80 \%$ of time in a multi-year rotation. Alternatively, perennial cover might be applied at particular times to compensate for losses of grasslands in other parts of the landscape. Perennial cover can also be used in rotations to provide soil erosion control during intense spring and autumn rainfall by conversion to annual crops in mid-spring after winter run-off, or planting to perennial cover in late-summer. Examples of this are the conversion of hay after a late spring harvest in order to grow corn, or the planting of a forage in late summer after harvest of a winter-annual cereal such as wheat. 
If rotations between perennial plants and annual crops can be strategically timed, they can extend predator habitat for crop pests like aphids (Rotem and Ziv 2016), reduce drainage discharge volumes_-and stream erosion-during peak flow periods, and slow nitrate nitrogen loss (Randall et al. 1997). Strategic timing can also increase the amount of organic nitrogen fixation by legumes such as clovers and alfalfa and strategic durations can contribute to weed control (Davis et al. 2012). The Marsden Farm experiments in central Iowa have shown the multiple benefits of perennial cover in a rotation sequence that has nearly disappeared from Midwestern agriculture (Jordan and Warner 2010; Davis et al. 2012). Similarly, thirty-year agricultural research station experiments in southern Canada demonstrate the benefits of perennial cover for improving soil structure and crop yields (Munkholm et al. 2013).

A proposed "50-Year Farm Bill” (Jackson 2010) suggests that $80 \%$ of farmlands should be perennial vegetation to achieve a more-sustainable agriculture. Recognizing that some of these perennial cover types might be rotated with annual crops, the $80 \%$ target could include dynamism. Targets like this require thinking not only of where perennials and annuals are located in the landscape, but also when they are in the landscape.

\section{Crop rotations and colored-string-of-lights}

Integrating the colored-string-of-lights metaphor with common rotations in central North American agriculture illustrates the dynamic sequences of cropping and identifies potential intervention opportunities. The colors in a changing string-of-lights can be imagined as representing a few common farm landcover types: yellow for corn, red for soybeans, orange for wheat (or other cereal grains), green for hay, blue for pasture. In a crop farm in the US Midwest, a common color sequence is likely to be an annual blinking on-and-off of yellow-red in repetition because a corn-soybean rotation is common. A similar farm in southern Ontario would have yellow-red-orange in a repetitive sequence, but the red to orange sequence would be within a single cropping season (e.g., soybeans sown in May; wheat sown in September after soybean harvest).
The agricultural landscape in central North America a century ago would be represented by a string of lights that was dominated by green and blue, with occasional blinking lights colored yellow and orange (red would have been less common) while other colors representing crops like oats and peas would appear (Waters 1915). The rate of blinking would have been slow-with green/blue lasting for many sequences and short bursts of yellow or orange before returning to green/blue. Any string-of-colored-lights with long green/blue dominance and infrequent yellow, orange, or red illumination would be likely to have lower soil erosion, better water quality, greater landscape heterogeneity, and other benefits.

Returning to that same agricultural landscape today the most-likely outcome is that yellow and red would be much more common, with orange in the cereal grain producing regions (Hudson 1992). The color sequence would have annual or sub-annual blinking rates. Green and blue would be greatly diminished and present for shorter periods (faster blinking). If the string is watched carefully over sequences of the last 10 years, the disappearance of green and blue might be noticeable (Stuart and Gillon 2013; Corry 2018). The dramatic shift between the landscape of a century ago and one today would be one of green/blue to yellow/ red/orange domination and one where green/blue lights changed color infrequently to a more rapid change of colors.

Finally, if the string-of-lights for a Midwestern (USA) agricultural landscape was observed just prior to the mid-1980s advent of the Conservation Reserve Program until the early 2010s, a number of yellow-red sequences would transition to green with slow blinking rates, only to transition back to yellow-redslowly at first - then faster and with a predominance of yellow coincident with national incentives for cornstarch ethanol (Stuart and Gillon 2013; Wright and Wimberly 2013).

\section{Designed string-of-light sequences}

Anyone who has purchased color-changing decorative light strings might have been selective about the available colors, the sequence of change, and the ability to control the change of colors. Design of the agricultural landscape is similar because the types of landcovers should be matched to landscape suitability 
(e.g., USDA NRCS land capability classification (Klingebiel and Montgomery 1961) or Canada's land inventory rating for agriculture (Hills 1961)), the change to the desired sequencing of cover types over short and long time periods, and the ability to change the landcovers and sequencing. This design might be desired "for the purpose of sustainably providing ecosystem services while recognizably meeting societal needs and respecting societal values" (Nassauer and Opdam 2008, p. 835) by changing agricultural landscape patterns (Nassauer et al. 2007; Jordan and Warner 2010; Lin 2011; Franzluebbers et al. 2014; Bartuszevige et al. 2016; Blanco-Canqui and Francis 2016; Landis 2017).

Substantial re-designs of agricultural landscape patterns might be met with societal—and in particular, farmer resistance (Knowler and Bradshaw 2007). However, leveraging a common agronomic practice in ways that support productive cropping might be more acceptable to farm decision-makers. A modest design intervention to change the consequences of agricultural landscape patterns would be to increase the perennial composition within a crop rotation sequence: that is, to increase the number of blue or green lights in a sequence or to extend their duration of lighting or brightness. A cropping sequence of cornsoybeans-cereal grain with an addition of a perennial legume improves soil structure, resource efficiency, nutrient and soil loss, and drainage volume (Huggins et al. 2001; Davis et al. 2012; Munkholm et al. 2013). Setting targets for how many of the bulbs in a stringof-lights have a particular color, how long they are lit, and how brightly they shine is a matter of temporal and spatial design. While incentivizing particular farm commodities or produce can be considered trade distortion, using incentives or regulations for agrienvironmental measures such as land cover composition are acceptable under trade agreements such as those affecting North American commodity markets (e.g., NAFTA, CETA, or CPTPP; Nassauer and Wascher 2007). The means to make such changes include comprehensive agri-environmental schemes like the Conservation Reserve Program or variations within agronomic rotation practices. These could include expectations for perennial composition of crop rotations for eligibility in publicly-subsidized crop insurance programs (Cox et al. 2011).

\section{Synthesis}

Wu (2012) noted that landscape pattern measures, pattern optimization, and landscape complexity and dynamics are research priorities within the field. Useful metaphors are fundamental for landscape ecologists to understand, imagine, and communicate constructs in trans-disciplinary discourse (Larson 2011). The string-of-lights metaphor, extended to a string of blinking, colored lights, applies to landscape composition, dynamics, and optimal design to achieve a desired level of vegetation types and timing that delivers expected benefits. Lights [representing patches] in strings [representing landscapes] can be imagined to blink in color sequences indicative of their composition and rates of change. The same can be applied to other landscape processes like sub-population dispersal and re-colonization. Encouraging specific, optimum, dynamic compositions by design is a matter of prioritizing the colors of lights in a string.

In agriculture, agronomically-designed crop rotation sequences are an auspicious point where a slight deflection can change the trajectory of the agricultural landscape in the short term (e.g., seasonally, or across a few years of a rotation). Design that alters the proportion, frequency, duration, or quality of perennial cover within crop rotations could be a way to become more-sustainable while meeting productivity expectations. In the rapidly-dynamic landscape of agricultural production, rotations and quickly-established cover types (e.g., herbaceous perennials like alfalfa hay or tame grasses) might be the mostaccessible way of designing new, more-sustainable agricultural landscape patterns - strings of colored blinking lights with an acceptable palette, a desired sequence, and an opportunity for influence-that respect societal values for care and stewardship of farmlands.

\section{References}

Asbjornsen H, Hernandez-Santana V, Liebman M, Bayala J, Chen J, Helmers M, Ong CK, Schulte LA (2013) Targeting perennial vegetation in agricultural landscapes for enhancing ecosystem services. Renew Agric Food Syst 29(02):101-125

Bartuszevige AM, Taylor K, Daniels A, Carter MF (2016) Landscape design: integrating ecological, social, and 
economic considerations into conservation planning. Wildl Soc Bull 40(3):422-435

Best LB, Freemark KE, Dinsmore JJ, Camp M (1995) A review and synthesis of habitat use by breeding birds in agricultural landscapes of Iowa. Am Midl Nat 134(1):1-29

Blanco-Canqui H, Francis C (2016) Building resilient soils through agroecosystem redesign under fluctuating climatic regimes. J Soil Water Conserv 71(6):127A-133A

Brown PW, Schulte LA (2011) Agricultural landscape change (1937-2002) in three townships in Iowa, USA. Landsc Urban Plan 100(3):202-212

Burger LW Jr, McKenzie D, Thackston R, Demaso SJ (2006) The role of farm policy in achieving large-scale conservation: Bobwhite and buffers. Wildl Soc Bull 34(4):986-993

Cachelin A, Norvell R, Darling A (2010) language fouls in teaching ecology: why traditional metaphors undermine conservation literacy. Conserv Biol 24(3):669-674

Congreves KA, Smith JM, Nemeth DD, Hooker DC, Van Eerd LL (2014) Soil organic carbon and land use: processes and potential in Ontario's long-term agro-ecosystem research sites. Can J Soil Sci 94(3):317-336

Corry RC (2016) Global and local policy forces for landscape perennialization in central North American agriculture. Geogr Tidsskr-Den 116(1):5-13

Corry RC (2018) Recent losses of perennial cover in a Great Lakes agricultural region. Can Geogr/Le Géographe canadien 62(2):178-187

Cox C, Hug A, Bruzelius N (2011) Losing ground. Environmental Working Group, Washington, DC, p 37

Davis AS, Hill JD, Chase CA, Johanns AM, Liebman M (2012) Increasing cropping system diversity balances productivity, profitability and environmental health. PLoS ONE 7(10):e47149

Dessureault D (2014) Canada biofuels annual. United States Department of Agriculture, Foreign Agricultural Service, Washington, DC, p 30

Dunn CP, Stearns F, Guntenspergen GR, Sharpe DM (1993) Ecological benefits of the Conservation Reserve Program. Conserv Biol 7(1):132-139

Eilers W, MacKay R, Graham L, Lefebvre A (eds) (2010) Environmental Sustainability of Canadian Agriculture, Report \#3. Agriculture and AgriFood Canada, Ottawa

Forman RTT (1993) An 'aggregate-with-outliers' land planning principle, and the major attributes of a sustainable environment. In: International Conference on Landscape Planning and Environmental Conservation, University of Tokyo, Tokyo, Japan, pp. 71-95

Forman RTT, Godron M (1986) Landscape Ecology. Wiley, Toronto

Franzluebbers AJ, Paine LK, Winsten JR, Krome M, Sanderson MA, Ogles K, Thompson D (2012) Well-managed grazing systems: a forgotten hero of conservation. J Soil Water Conserv 67(4):100a-104a

Franzluebbers AJ, Sawchik J, Taboada MA (2014) Agronomic and environmental impacts of pasture-crop rotations in temperate North and South America. Agric Ecosyst Environ 190:18-26

Freemark KE (1999) Farmlands for farming and nature. In: Wiens JA, Oss MR (eds) Issues in landscape ecology. The
International Association for Landscape Ecology, Guelph, pp 124-128

Fuglie KO (1999) Conservation tillage and pesticide use in the cornbelt. J Agric Appl Econ 31(1):133-147

Gaudin ACM, Tolhurst TN, Ker AP, Janovicek K, Tortora C, Martin RC, Deen W (2015) Increasing crop diversity mitigates weather variations and improves yield stability. PLoS ONE 10(2):1-20

Gunderson LH, Holling CS, Light SS (1995) Barriers and bridges to the renewal of ecosystems and institutions. Columbia University Press, New York

Hanski I (1998) Metapopulation dynamics. Nature 396(6706):41-49

Henningsen JC, Best LB (2005) Grassland bird use of riparian filter strips in southeast Iowa. J Wildlife Manage 69(1): 198-210

Hills GA (1961) The ecological basis for land-use planning. Ontario Department of Lands and Forests, Toronto, p 204

Hudson JC (1992) Crossing the heartland: Chicago to Denver. Rutgers University Press, New Brunswick, New Jersey

Huggins DR, Randall GW, Russelle MP (2001) Subsurface drain losses of water and nitrate following conversion of perennials to row crops. Agron J 93(3):477-486

Jackson W (2010) Consulting the genius of the place. Counterpoint, Berkeley

Jordan N, Warner KD (2010) Enhancing the multifunctionality of US agriculture. Bioscience 60(1):60-66

Klingebiel AA, Montgomery PH (1961) Land-Capability Classification: Agriculture Handbook No. 210. United States Department of Agriculture, Soil Conservation Service, Washington, DC, pp. 21

Knowler D, Bradshaw B (2007) Farmers' adoption of conservation agricutlure: a review and synthesis of recent research. Food Policy 32:25-48

Landis DA (2017) Designing agricultural landscapes for biodiversity-based ecosystem services. Basic Appl Ecol 18:1-12

Larson B (2011) Metaphors for environmental sustainability. Yale University Press, New Haven

Lemaire G, Gastal F, Franzluebbers A, Chabbi A (2015) Grassland-cropping rotations: an avenue for agricultural diversification to reconcile high production with environmental quality. Environ Manage 56(5):1065-1077

Liebman M, Schulte LA (2015) Enhancing agroecosystem performance and resilience through increased diversification of landscapes and cropping systems. Elementa-Sci Anthrop 3:000041

Lin BB (2011) Resilience in agriculture through crop diversification: adaptive management for environmental change. Bioscience 61(3):183-193

Lockeretz W (ed) (1997) Visions of American agriculture. Iowa State University, Ames

Munkholm LJ, Heck RJ, Deen B (2013) Long-term rotation and tillage effects on soil structure and crop yield. Soil Till Res 127:85-91

Nassauer JI, Kling CL (2007) Changing societal expectations for environmental benefits from agricultural policy. In: Nassauer JI, Santelmann MV, Scavia D (eds) From the corn belt to the Gulf: societal and environmental implications of alternative agricultural futures. Resouces for the Future Press, Washington, DC, pp 28-39 
Nassauer J, Opdam P (2008) Design in science: extending the landscape ecology paradigm. Landscape Ecol 23(6):633-644

Nassauer JI, Santelmann MV, Scavia D (eds) (2007) From the corn belt to the Gulf: societal and environmental implications of alternative agricultural futures. Resources for the Future Press, Washington, DC

Nassauer JI, Wascher DM (2007) The globalized landscape: rural landscape change and policy in the United States and European Union. In: Wescoat J, Johnston D (eds) Political economies of landscape change. Springer, Dordrecht, pp 169-194

Opdam P, Nassauer JI, Wang Z, Albert C, Bentrup G, Castella JC, McAlpine C, Liu J, Sheppard S, Swaffield S (2013) Science for action at the local landscape scale. Landscape Ecol 28(8):1439-1445

Opdam P, Van Apeldoorn R, Schotman A, Kalkhoven J (1993) Population responses to landscape fragmentation. In: Vos CC, Opdam P (eds) Landscape ecology of a stressed environment. Chapman and Hall, New York, pp 147-169

Pan D, Domon G, de Blois S, Bouchard A (1999) Temporal (1958-1993) and spatial patterns of land use changes in Haut-Saint-Laurent (Quebec, Canada) and their relation to landscape physical attributes. Landscape Ecol 14:35-52

Potter P, Ramankutty N, Bennett EM, Donner SD (2010) Characterizing the spatial patterns of global fertilizer application and manure production. Earth Interact 14(2): $1-22$

Ramankutty N, Evan AT, Monfreda C, Foley JA (2008) Farming the planet: 1. Geographical distribution of global agricultural lands in the year 2000. Glob Biogeochem Cycles 22:1003

Randall GW, Huggins DR, Russelle MP, Fuchs DJ, Nelson WW, Anderson JL (1997) Nitrate losses through subsurface tile drainage in Conservation Reserve Program, alfalfa, and row crop systems. J Environ Quality 26:1240-1247

Riffell S, Scognamillo D, Burger LW (2008) Effects of the Conservation Reserve Program on northern bobwhite and grassland birds. Environ Monit Assess 146(1-3):309-323

Rotem G, Ziv Y (2016) Crop diversity and rotation may increase dispersal opportunities of reptiles in a heterogeneous agroecosystem. Agric Ecosyst Environ 235:32-37

Russelle MP, Entz MH, Franzluebbers AJ (2007) Reconsidering integrated crop-livestock systems in North America. Agron J 99(2):325-334

Santelmann MV, White D, Lindsay K, Nassauer JI, Eilers JM, Vaché KB, Danielson BJ, Corry RC, Clark ME, Polasky S, Cruse RM, Sifneos J, Rustigian H, Coiner C, Wu J, Debinski D (2007) An integrated assessment of alternative futures for agriculture in the corn belt. In: Nassauer JI, Santelmann MV, Scavia D (eds) From the corn belt to the Gulf: ecological and social implications of alternative agricultural futures. Resources for the Future Press, Washington, DC, pp 162-174

Schnepf R, Yacobucci BD (2012) Renewable Fuel Standard (RFS): overview and issues. Congressional Research Service, Washington, DC, p 29

Schulte LA, Liebman M, Asbjornsen H, Crow TR (2006) Agroecosystem restoration through strategic integration of perennials. J Soil Water Conserv 61(6):165A-169A

Smil V (2001) Enriching the Earth: Fritz Haber, Carl Bosch, and the transformation of world food production. The MIT Press, Cambridge

Soil Conservation Society of America (1982) Resource conservation glossary. In: Sanders J (ed) Soil Conservation Society of America, 3rd edn. Ankeny, Iowa, p 193

Soule JD, Piper JK (1992) Farming in nature's image: an ecological approach to agriculture. Island Press, Washington, DC

Sparrow HO (1984) Soil at risk: Canada's eroding future. Senate of Canada, Ottawa

Steiner FR (1990) Soil conservation in the United States: policy and planning. Johns Hopkins University Press, Baltimore

Stuart D, Gillon S (2013) Scaling up to address new challenges to conservation on US farmland. Land Use Policy 31:223-236

Thompson JR, Carpenter DN, Cogbill CV, Foster DR (2013) Four centuries of change in Northeastern United States Forests. PLoS ONE 8(9):1-15

Tilman D, Cassman KG, Matson PA, Naylor R, Polasky S (2002) Agricultural sustainability and intensive production practices. Nature 418(6898):671-677

Tscharntke T, Tylianakis JM, Rand TA, Didham RK, Fahrig L, Batáry P, Bengtsson J, Clough Y, Crist TO, Dormann CF, Ewers RM, Fründ J, Holt RD, Holzschuh A, Klein AM, Kleijn D, Kremen C, Landis DA, Laurance W, Lindenmayer D, Scherber C, Sodhi N, Steffan-Dewenter I, Thies C, van der Putten WH, Westphal C (2012) Landscape moderation of biodiversity patterns and processes-eight hypotheses. Biol Rev Camb Philos Soc 87(3):661-685

Waters HJ (1915) The essentials of agriculture. Ginn and Company, Boston

Wright CK, Wimberly MC (2013) Recent land use change in the Western Corn Belt threatens grasslands and wetlands. Proc Natl Acad Sci USA 110(10):4134-4139

Wu J (2012) Landscape ecology. In: Myers RA (ed) Encyclopedia of sustainability science and technology, 1st edn. Springer, New York, p 12555 